Diabetologia (1994) 37: 879-884

Diabetologia

(C) Springer-Verlag 1994

\title{
Insulin secretion in rats with chronic nitric oxide synthase blockade
}

\author{
M. E. Pueyo ${ }^{1}$, W. Gonzalez ${ }^{1}$, E.Pussard ${ }^{2}$, J.F.Arnal ${ }^{1}$ \\ ${ }^{1}$ INSERM U 367, Paris, France \\ ${ }^{2}$ Pharmacology Department, Kremlin-Bicêtre Hospital, Kremlin-Bicêtre, France
}

Summary Nitric oxide, which is produced from L-arginine by a nitric oxide-synthase enzyme, has been shown to be a ubiquitous messenger molecule. Recently, it has been suggested that nitric oxide might influence insulin secretion by activating the soluble guanylate cyclase and generating cyclic guanosine monophosphate (cGMP). We have investigated the role of the nitric oxide pathway in insulin secretion by evaluating the insulin response to several secretagogues in rats in which nitric oxide-synthase was chronically inhibited by oral administration of the L-arginine analogue, $\mathrm{N}^{\mathrm{G}}$-nitro-L-arginine methyl ester (LNAME). Blood pressure and aortic wall cGMP content were used as indices of nitric oxide-synthase blockade. Insulin secretion was evaluated after an intravenous bolus of $\mathrm{D}$-glucose, $\mathrm{L}$-arginine or $\mathrm{D}$-arginine. Chronic L-NAME administration induced a $30 \%$ increase in blood pressure and a seven-fold drop in ar- terial cGMP content. Body weight, fasting plasma glucose and insulin were not influenced by L-NAME administration. First-phase insulin secretion $(1+3 \mathrm{~min})$ in response to glucose was not significantly different in L-NAME and control rats. The areas under the insulin curve were similar in both groups. Insulin secretion in response to $D$-arginine or $\mathrm{L}$-arginine in L-NAME-treated and control rats were also similar. In conclusion, chronic nitric oxide-synthase blockade increases blood pressure and decreases aortic cGMP content, but does not alter insulin secretion in response to several secretagogues. Chronic oral administration of $\mathrm{L}-\mathrm{NAME}$ in the rat provides an adequate animal model for studying the L-arginine nitric oxidepathway. [Diabetologia (1994) 37: 879-884]

Key words Insulin secretion, nitric oxide, in vivo, LNAME, Wistar rats.
Nitric oxide (NO), initially identified as an endothelium-derived relaxing factor [1], has been shown to be a ubiquitous messenger molecule [2]. It is produced in several tissues, such as the vascular endothelium, neurones and immune cells and has a very short half-life [3]. It can diffuse from secreting cells and activate biochemical processes in neighbouring cells, serving a wide

Received: 3 January 1994

and in revised form: 20 April 1994

Corresponding author: Dr. M.E.Pueyo, INSERM U 367 , 17, Rue du Fer à Moulin, F-75005 Paris, France

Abbreviations: NO, Nitric oxide; cGMP, guanosine 3': 5' cyclic monophosphate; L-NMMA, $\mathrm{N}^{\mathrm{G}}$-monomethyl-L-arginine; LNAME, $\mathrm{N}^{\mathrm{G}}$-nitro-L-arginine-methyl-ester, NOD mice, non obese diabetic mice. variety of functions in different tissues. In arterial walls, NO produced by endothelial cells stimulates the soluble guanylate cyclase of the underlying smooth muscle cells leading to the generation of cGMP and subsequent relaxation. In certain discrete neurone populations of the central nervous system, NO behaves as a neurotransmitter and neuromodulator [4]. In activated neutrophils and macrophages, secretion and metabolism of NO leads to the formation of free radicals. These free radicals, as well as NO itself, may account for some of the cytotoxic effects of these cells $[5,6]$.

$\mathrm{NO}$ is produced from $\mathrm{L}$-arginine by the enzyme NOsynthase. Two different types of NO-synthase have been described: a constitutive one, with at least two isoforms (endothelial and neuronal) [7, 8], and an inducible NO-synthase, first described in macrophages, but shown to be present in several cell types [6]. 
Table 1. Clinical and metabolic parameters after 4 weeks of L-NAME administration in rats

\begin{tabular}{llccc}
\hline & $n$ & L-NAME & Controls & $p$-value \\
\hline Body weight (g) & 16 & $378 \pm 11$ & $370 \pm 10$ & NS \\
Blood pressure (mm Hg) & 16 & $175 \pm 3$ & $133 \pm 2$ & $<0.0001$ \\
Heart rate & 16 & $358 \pm 8$ & $336 \pm 9$ & NS \\
Aortic cGMP content (fmol/mg protein) & 16 & $276 \pm 28$ & $1853 \pm 192$ & $<0.0001$ \\
Plasma norepinephrine (nmol/1) & 9 & $10 \pm 1$ & $13 \pm 2$ & NS \\
Plasma epinephrine (nmol/l) & 9 & $34 \pm 2$ & $34 \pm 3$ & NS \\
\hline
\end{tabular}

Results of recent studies in the rat suggest that NO could play a role in glucose-induced insulin secretion and be an important mediator of L-arginine-induced insulin release. The constitutive form of $\mathrm{NO}$-synthase was detected by immuno-histochemistry in the islets of Langerhans and NO-synthase blockade suppressed cGMP generation and insulin secretion [9]. However, the suppression of insulin release by isolated islets after NO-synthase blockade was not confirmed in two other studies $[10,11]$. Furthermore, it is controversial whether the constitutive NO-synthase observed in pancreatic islets is present in neuronal ganglia [12] or in the endocrine cells $[9,13]$. However, the restriction of NO-synthase to vascular or neuronal cells within the islets, does not exclude a participation of NO generation in the mechanisms of insulin secretion. Indeed, in tissues such as the arterial wall, NO has been shown to diffuse from secreting cells and to activate biochemical processes in neighbouring cells. It is therefore, important to evaluate the role of NO generation in insulin secretion in vivo.

Arginine analogues such as $\mathrm{N}^{\mathrm{G}}$-monomethyl-L-arginine (L-NMMA) and $\mathrm{N}^{\mathrm{G}}$-nitro-L-arginine-methylester (L-NAME) block NO production. Both the endothelial and the neuronal NO-synthases, as well as the inducible NO-synthase, appear to be sensitive to these arginine analogues [14] in several types of cells, including islets of Langerhans $[10,15,16]$. Chronic administration of L-NAME in rats provides a novel model of hypertension in which NO-synthase can be dose-dependently blocked [17]. These animals also provide an adequate model with which to investigate the role of the NO pathway in the mechanisms of insulin secretion. This report describes the in vivo insulin responses to i. v. glucose, D-arginine and L-arginine in Wistar rats chronically treated with L-NAME.

\section{Materials and methods}

Chronic blockade of NO-synthase in vivo. Twenty-five adult male Wistar rats (9-10 weeks old, 250 g body weight, Charles River, Saint Aubin Lés Elbeuf, France) were given L-NAME $\left(50 \mathrm{mg} \cdot \mathrm{kg}^{-1} \cdot\right.$ day $^{-1}$; Sigma, St Louis, Mo., USA) in the drinking water for 4 weeks. This dose causes maximal NO-synthase blockade with sustained hypertension [17]. Twenty-five control rats were given water alone. All animals were fed ad libitum.

Blood pressure and aortic cGMP content were studied as indices of NO-synthase blockade after 4 weeks of L-NAME administration. Systolic blood pressure and heart rate were measured by the tail-cuff method ( $W+W$ electronic recorder model 8005; Apelab, Bagneux, France) in conscious rats. The cGMP content in the aorta was measured as follows: after the metabolic experiments, the thoracic aortas were excised, rinsed in cold phosphate-buffered saline, frozen in liquid nitrogen, and homogenised in 10 volumes $0.1 \mathrm{~N} \mathrm{HCl}$ with an all-glass homogeniser at $4^{\circ} \mathrm{C}$. The homogenates were neutralised with $\mathrm{NaOH}$ and centrifuged at $15,000 \mathrm{~g}$ for $30 \mathrm{~min}$. Aliquots of the supernatants were stored at $-20^{\circ} \mathrm{C}$ until assayed.

Catecholamines were measured to evaluate possible bias in insulin secretion due to potential effects of NO-synthase blockade on adrenal medullar function [18]. For this assay, a group of nine L-NAME-treated and nine control rats were killed by decapitation. Blood samples were drawn into tubes containing EDTA $(1 \mathrm{mg} / \mathrm{ml})$, centrifuged at $3000 \mathrm{rpm}$ for $10 \mathrm{~min}$ and stored at $-80^{\circ} \mathrm{C}$.

Insulin secretion studies. Overnight fasted L-NAME and control rats were anaesthetised with pentobarbital $(75 \mathrm{mg} / \mathrm{kg}$ i.p.) and catheters were inserted in a jugular vein and homolateral carotid artery. Bolus of $30 \%$ glucose $(0.8 \mathrm{mg} / \mathrm{kg} ; n=6 \mathrm{in}$ each group), D-arginine (100 $\mathrm{mg} / \mathrm{kg} ; n=5)$ or L-arginine $(60 \mathrm{mg} /$ $\mathrm{kg} ; n=5$ ) were injected in the jugular vein over $15 \mathrm{~s}$. Time 0 min was the end of the injection. Blood was sampled into heparinised tubes for glucose and insulin measurements at $-5,1,3,5$, 10,15 and $30 \mathrm{~min}$.

Analytical procedures. Glucose concentration was measured by the glucose-oxidase method (Beckman glucose analyzer II; Beckman, Fullerton, Calif., USA). Plasma insulin was determined by radioimmunoassay with a commercial kit (CEA, Saclay, France) using a rat insulin standard. cGMP was measured by radioimmunoassay using a polyclonal antibody against succinyl cGMP [17]. Plasma catecholamines were assessed by high performance liquid chromatography with electrochemical detection [19].

\section{Statistical analysis}

Data are expressed as means \pm SEM and range. The groups were compared with the Mann Whitney $U$ test for non-parametric data. Statistical significance was defined as $p<0.05$.

\section{Results}

None of the rats died during the 4-week administration of L-NAME. The body weights of treated and control animals were not significantly different (Table 1). At the end of week 4, systolic blood pressure was significantly higher in L-NAME rats, and their aorta cGMP content was decreased by seven-fold as compared to the control group. These results are con- 

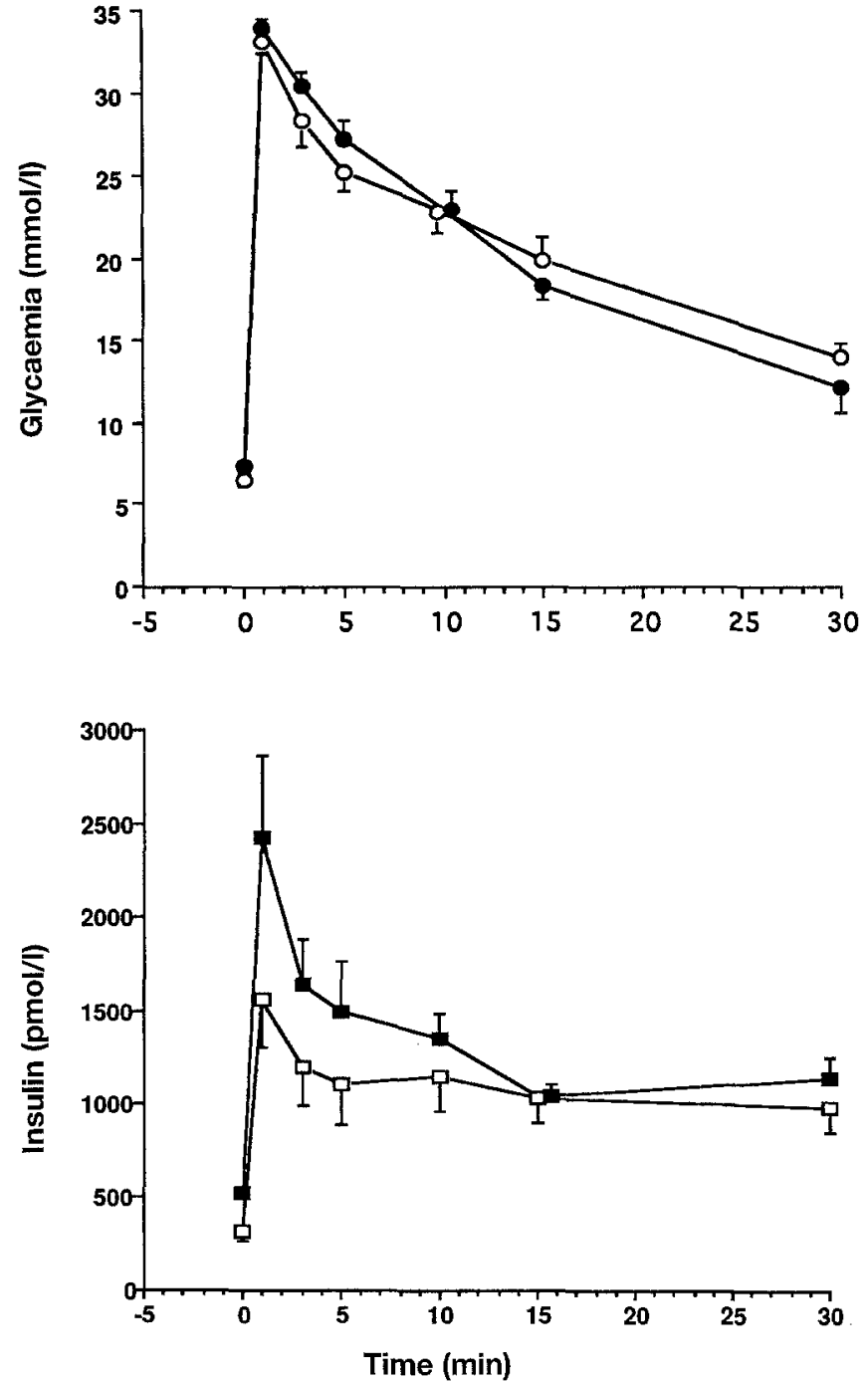

Fig. 1. Plasma glucose (top panel) and insulin (bottom panel) after an i. v. bolus of D-glucose in rats treated for 4 weeks by LNAME $(\bullet ; n=6)$ and in control rats $(0 ; n=6)$. Results are mean \pm SEM of six experiments. No difference was observed of insulin secretion peak $(1+3 \mathrm{~min})$ or area under the curve between the two groups

sistent with an effective chronic blockade of NO-synthase. The heart rate and the plasma epinephrine and norepinephrine concentrations were not significantly different in both groups (Table 1).

The fasting plasma glucose and insulin levels were not significantly altered by L-NAME treatment: $7.0 \pm 0.3$ (range 6.5-7.9) vs $6.6 \pm 0.3$ (range 5.9-7.9) $\mathrm{mmol} / \mathrm{l}$ glucose, and $329 \pm 57$ (range 128-533) vs $324 \pm 43$ (range 96-427) pmol/l insulin, respectively in L-NAME and control rats. One minute after the injection of a glucose bolus, plasma glucose peaked at $34.4 \pm 0.5$ (range $32.6-35.6$ ) $\mathrm{mmol} / \mathrm{l}$ in L-NAME rats and $33.5 \pm 0.7$ (range $31.9-35.6$ ) $\mathrm{mmol} / \mathrm{l}$ in controls (NS; Fig. 1). The first-phase insulin secretion (values of time $1+3 \mathrm{~min}$ ) was higher in L-NAME rats than in controls: $4074 \pm 555$ (range 2236-5323) vs $2695 \pm 397$ (range 1852-4018) pmol/l, although not significantly

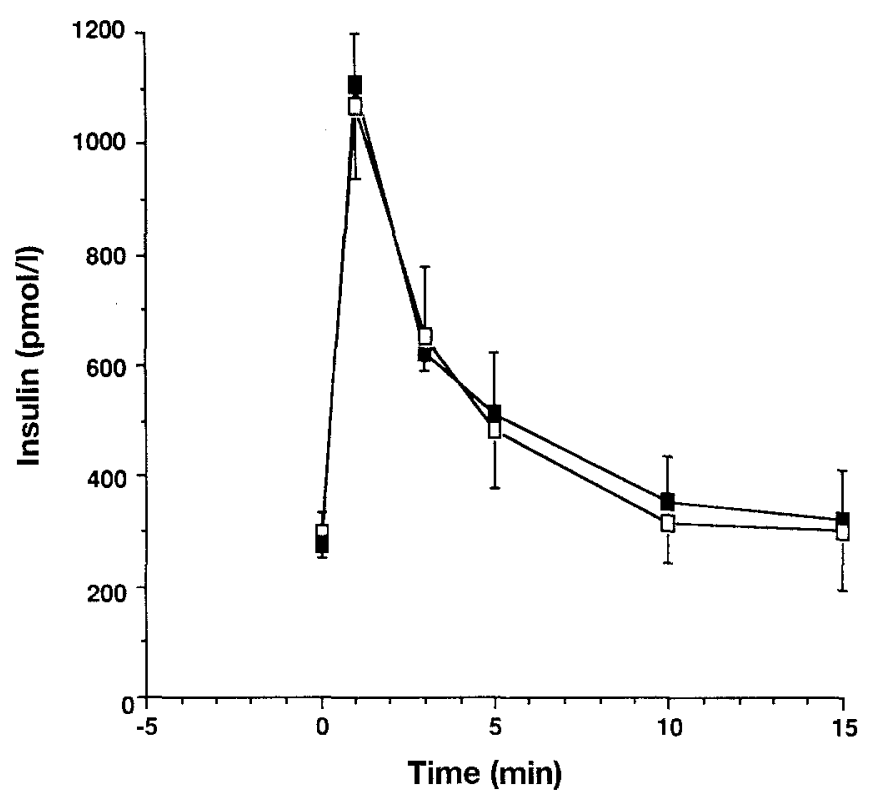

Fig. 2. Plasma insulin after an i.v. bolus of $L$-arginine in rats treated for 4 weeks by L-NAME ( $\boldsymbol{m}$ ) and in control rats ( $\square$ ). Results are mean \pm SEM of five experiments. No difference was observed of insulin secretion peak or area under the curve between the two groups

different. The area under the insulin curve (time 0$15 \mathrm{~min}$ ) reflects the overall response to glucose during the test. Again values in the two groups were not significantly different: $21.5 \pm 2.3$ vs $16.7 \pm 2.8 \mathrm{nmol}$. $\mathrm{1}^{-1} \cdot \mathrm{min}^{-1}$ in L-NAME and control rats, respectively.

The insulin secretion responses to both L-arginine (Fig. 2) and D-arginine (Fig. 3) were not significantly different in L-NAME and in control rats. One minute after the L-arginine injection plasma insulin peaked at $1108 \pm 170$ (range 688-1586) pmol/1 in L-NAME rats and at $1069 \pm 131$ (range 780-1296) pmol/l in the controls. The area under the insulin curve $(0-15 \mathrm{~min})$ was $7.3 \pm 1.5 \mathrm{vs} 7.1 \pm 1.3 \mathrm{nmol} \cdot \mathrm{l}^{-1} \cdot \mathrm{min}^{-1}$, respectively in L-NAME and control animals. One minute after the injection of D-arginine, plasma insulin peaked at $695 \pm 155$ (range 392-1091) pmol/l in L-NAME rats and at $700 \pm 143$ (range 457-1108) pmol/l in the controls. The area under the insulin curve $(1-15 \mathrm{~min})$ in response to $\mathrm{D}$-arginine was $10.4 \pm 0.8$ in $\mathrm{L}-\mathrm{NAME}$ rats and $8.7 \pm 1.7 \mathrm{nmol} \cdot 1^{-1} \cdot \mathrm{min}^{-1}$ in control rats.

\section{Discussion}

L-Arginine potentiates D-glucose-induced insulin release, and is the most powerful amino acid stimulus of insulin secretion. The mechanisms of the insulinotropic action of arginine and of the glucose/arginine interaction are largely unknown. It has been suggested that the accumulation of arginine, a positively charged molecule, inside beta cells leads to depolarisation of the plasma membrane and eventually to insulin secretion as a purely biophysical effect [20]. 


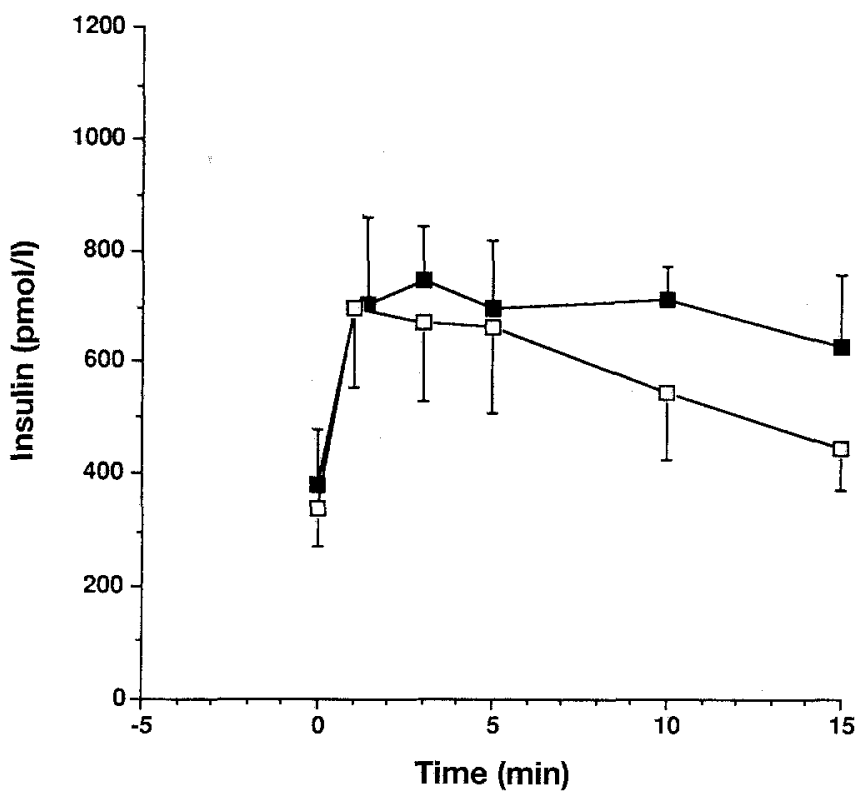

Fig.3. Plasma insulin after an i.v. bolus of $D$-arginine in rats treated for 4 weeks by L-NAME ( $\boldsymbol{\square}$ ) and in control rats ( $\square$ ). Results are mean \pm SEM of five experiments. No difference was observed of insulin secretion peak or area under the curve between the two groups

However, it is known that arginine is metabolised in pancreatic islets via several pathways with the resulting conversion in L-ornithine and urea, or L-glutamate, and generation of polyamines [21]. The part that these reactions might take in the insulinotropic action of arginine is not fully understood [22]. NO generation from $\mathrm{L}$-arginine by $\mathrm{NO}$-synthase, leading to the activation of soluble guanylate cyclase and cGMP generation, is an interesting alternative explanation for the L-arginine insulinotropic effects. It has also been suggested that the NO-pathway might also play a role in glucose-induced insulin release [9]. However, experimental evidence supporting these hypotheses is controversial [11].

We report here the evaluation of insulin secretion in a rat model with chronic NO-synthase blockade by oral administration of L-NAME. The effectiveness of NO-synthase blockade in these rats is demonstrated by a sustained increase in blood pressure, and by a seven-fold decrease in aortic cGMP content, which depends mainly on NO-synthase activity in this tissue $[23,24]$. The reliability of the NO-synthase blockade is proved by the high dose of L-arginine $(>1000 \mathrm{mg} / \mathrm{kg}$ i.v.) needed to reverse the hypertension [17]. Normal fasting plasma glucose and insulin levels were observed in L-NAME-treated animals. Furthermore, the insulin secretion in response to $i$. v. glucose, D-arginine and $\mathrm{L}$-arginine was comparable to control animals.

Our results are in agreement with in vitro studies showing that, although NO is a mediator of glucoseinduced cGMP production in islets, the resulting increase in cGMP levels is not correlated with insulin secretion $[10,11]$. We have observed that L-NAME administration in vivo markedly diminished NO-dependent cGMP production without affecting insulin secretion. These results indicate that increases in cGMP do not have an essential role in insulin secretion.

Interpretation of the L-arginine-induced insulin secretion results needs special attention. As L-arginine is known to reverse the NO-synthase blockade induced by its analogues $[3,17]$, this must be taken into account when evaluating L-arginine-induced insulin secretion. For this study, we have chosen a dose of $60 \mathrm{mg} / \mathrm{kg}$ of L-arginine, which is highly effective in inducing insulin secretion, but produces only a decrease in blood pressure of about $15 \mathrm{~mm} \mathrm{Hg}$ for less than $5 \mathrm{~s}$, suggesting that the chronic NO-synthase blockade is not reversed. Our results of L-arginine-induced insulin secretion were similar in controls and L-NAME rats, suggesting that $\mathrm{NO}$ production does not play a major role. Thus, NO generation may not explain why L-arginine seems to be more potent than $\mathrm{D}$-arginine in stimulating insulin secretion. It is important to note that arginine analogues specifically compete for the NOsynthase and do not affect other arginine-metabolizing enzymes such as arginase or arginine decarboxylase [25]. Furthermore, L-NAME, contrary to other arginine analogues, does not interfere with cell $\mathrm{L}$-arginine transport [26]. Thus, our results have no implications regarding the other proposed mechanisms of arginine-induced insulin release described above.

Data in the literature of similar in vivo studies are scarce. Schmidt et al. [9] reported decreased insulin secretion in response to i.v. glucose in rats acutely treated with methyl-arginine. However, it is difficult to interpret the reported results for two reasons: firstly, parameters for NO-synthase blockade were not assessed by the authors following the acute injection of methyl-arginine. Secondly, as insulin levels were evaluated only $5 \mathrm{~min}$ after the injection of D-glucose, the first phase of insulin secretion, which is a very sensitive parameter of beta cell dysfunction, was probably missed. It is also important to point out that an acute administration of L-arginine analogues might introduce a confounding bias in the evaluation of insulin secretion, at least under certain experimental conditions. Indeed, methyl-arginine was shown to have a stimulatory effect on insulin release by the perfused rat pancreas [27] and, we have observed that i.v. administration of L-NAME induces insulin secretion in the rat (data not shown).

Chronic oral administration of L-NAME for 4 weeks provides suitable chronic blockade of NOsynthase, and thus is an appropriate model with which to study the NO pathway in different physiological situations. Oral administration of L-NAME for shorter periods (up to 1 week) results in increased but labile blood pressure levels, which are significantly lower than the stable and markedly hypertensive levels observed from week 3 of treatment. Thus, this 
suggests that in the first days of the oral L-NAME administration, NO-synthase blockade might be only partial.

Chronic blockade of NO-synthase does not seem to interfere with the physiological integrity of the major endocrine systems in these rats. This is suggested by the normal growth and weight gain after 4 weeks of LNAME administration. We have also observed that plasma catecholamines, thyroid hormones (data not shown), and atrial natriuretic peptide [17] are in the normal range, and verified the integrity of the reninangiotensin-aldosterone system [17]. Finally, chronic administration of L-NAME to rats does not significantly alter the mesenteric blood flow [28], and inhibitors of NO-synthase do not interfere with the blood flow distribution within the isolated perfused pancreas [27]. Incidentally, it has been recently reported that acute administration of L-NMMA causes insulin resistance in rats [29]. This is not a particular feature of L-NAME-treated rats: we have observed that fasting plasma insulin was similar in both groups and insulin response to glucose, although higher in LNAME rats, was not significantly different. However, the experimental design of our study does not allow a proper assessment of insulin sensitivity.

These observations indicate that chronic oral administration of L-NAME to rats might provide a good model with which to study the role of the L-arginineNO pathway in physiological and physiopathological processes. For instance, several in vitro studies show that NO produced by macrophages [30] as well as cytokine-induced NO generation in insulin-secreting cells $[16,31]$ might be implicated in the dysfunction of these cells, associated with insulin-dependent diabetes mellitus $[15,16,30,31]$. NO-synthase blockade prevents these deleterious effects in vitro $[15,16,30]$, and delays the development of diabetes in NOD mice in vivo [32]. In vivo evaluation of the role of $\mathrm{NO}$ in beta cell damage would be of interest and applicable to this animal model.

In conclusion, our results suggest that NO generation in beta cells or in surrounding endothelial and neuronal cells, does not play a major role in arginine or glucose-induced insulin secretion, or in the chronic regulation of insulin secretion in response to these secretagogues. Chronic oral administration of L-NAME in the rat provides an adequate animal model for studying the L-arginine-NO pathway.

Acknowledgements. We are grateful to Dr. G. Reach for glucose and insulin measurements in his laboratory.

\section{References}

1. Palmer RMJ, Ferrige AG, Moncada S (1987) Nitric oxide release accounts for the biological activity of endotheliumderived relaxing factor. Nature 327: 524-526
2. Dinerman JL, Lowenstein CJ, Snyder SH (1993) Molecular mechanisms of nitric oxide regulation. Circ Res 73: 217-222

3. Moncada S, Palmer RMJ, Higgs EA (1991) Nitric oxide: physiology, pathophysiology and pharmacology. Pharmacol Rev 43: 109-142

4. Bredt DS, Hwang PM, Snyder SH (1990) Localization of nitric oxide synthase indicating a neural role for nitric oxide. Nature 347: 768-770

5. Radi R, Beckman JS, Bush KM, Freeman BA (1991) Peroxynitrite oxydation of sulfhydryls: the cytotoxic potential of superoxide and nitric oxide. J Biol Chem 266: 4244-4250

6. Nussler AK, Billiar TR (1993) Inflammation, immunoregulation, and inducible nitric oxide synthase. J Leukoc. Biol 54: 171-178

7. Lowenstein CJ, Synder SH (1992) Nitric oxide, a novel biologic messenger. Cell 70: 705-707

8. Knowles RG, Moncada S (1994) Nitric oxide synthases in mammals. Biochem J 298: 249-258

9. Schmidt HHHW, Warner TD, Ishii K, Sheng H, Murad F (1992) Insulin secretion from pancreatic B cells caused by Larginine-derived nitrogen oxides. Science 255: 721-723

10. Laychock SG, Modica ME, Cavanaugh CT (1991) L-arginine stimulates cyclic guanosine $3^{\prime} 5^{\prime}$-monophosphate formation in rat islet of Langerhans and RINm5F insulinoma cells: evidence for L-arginine: nitric oxide synthase. Endocrinology 129: 3043-3052

11. Jones PM, Persaud SJ, Bjaaland T, Pearson JD, Howell SL (1992) Nitric oxide is not involved in the initiation of insulin secretion from rat islets of Langerhans. Diabetologia 35: 1020-1027

12. Vincent SR (1992) Nitric oxide and arginine-evoked insulin secretion. Seience 258: 1376

13. Corbett JA, Wang JL, Misko TP, Zhao WG, Hickeky WF, McDaniel ML (1993) Nitric oxide mediates IL-1 $\beta$ induced islet dysfunction and destruction. Prevention by dexamethasone. Autoimmunity 15: 145-153

14. Lambert LE, Whitten JP, Baron BM, Cheng HC, Doherty NS, McDonald IA (1991) Nitric oxide synthesis in the CNS, endothelium and macrophages differs in its sensitivity to inhibition by arginine analogues. Life Sci 48: 69-75

15 . Southern C, Schulster D, Green IC (1990) Inhibition of insulin secretion by interleukin- $1 \beta$ and tumor necrosis factor$\alpha$ via an L-arginine-dependent nitric oxide generating mechanism. FEBS Lett 276: 42-44

16. Eizirik DL, Cagliero E, Björklund A, Welsh N (1992) Interleukin $-1 \beta$ induces the expression of an isoform of nitric oxide synthase in insulin-producing cells, which is similar to that observed in activated macrophages. FEBS Lett 308: 249-252

17. Arnal JF, Warin L, Michel JB (1992) Determinants of aortic cyclic guanosine monophosphate in hypertension induced by chronic inhibition of nitric oxide synthase. J Clin Invest 90: 647-652

18. Moro MA, Michelena P, Sanchez-García P, Palmer R, Moncada S, García AG (1993) Activation of adrenal medullary L-arginine: nitric oxide pathway by stimuli which induce the release of catecholamines. Eur J Pharmacol 246: 213-218

19. Causon RC, Carruthers ME, Rodnight R (1981) Assay of plasma catecholamines by liquid chromatography with electrochemical detection. Anal Biochem 116: 223-226

20. Blachier F, Leclercq-Meyer V, Marchand J et al. (1989) Stimulus-secretion coupling of arginine-induced insulin release. Functional response of islets to L-arginine and ornithine. Biochem Biophys Acta 1013: 144-151

21. Malaisse WJ, Blanchier F, Mourtada A et al. (1989) Stimulus-secretion coupling of arginine-induced insulin release. 
Metabolism of L-arginine and L-ornithine in pancreatic islets. Biochem Biophys Acta 1013: 133-143

22. Sener A, Blanchier F, Rasschaert J, Malaisse WJ (1990) Stimulus-secretion coupling of arginine-induced insulin release. Comparison with histidine-induced insulin release. Endocrinology 127: 107-113

23. Arnal JF, El Amrani AI, Michel JB (1993) Atrial natriuretic factor influences in vivo plasma, lung and aortic wall cGMP concentrations differently. Eur J Pharmacol 237: 265-273

24. Verspohl AJ, Ammon HPT (1989) Atrial natriuretic peptide acts via specific binding sites of cGMP system of rat pancreatic islets without affecting insulin release. Naunyn Schmiedebergs Arch Pharmacol 339: 348-353

25. Granger DL, Hibbs JB, Perfect JR, Durack DT (1990) Metabolic fate of $\mathrm{L}$-arginine in relation to microbiostatic capability of murine macrophages. J Clin Invest 85: 264-273

26. Bogle RG, Moncada S, Pearson JD, Mann GE (1992) Identification of inhibitors of nitric oxide synthase that do not interact with the endothelial cell $\mathrm{L}$-arginine transporter. $\mathrm{Br}$ J Pharmacol 105: 768-770

27. Jansson L, Sandler S (1991) The nitric oxide synthase II inhibitor $\mathrm{N}^{\mathrm{G}}$-nitro-L-arginine stimulates pancreatic islet insulin release in vitro, but not in the perfused pancreas. Endocrinology 128: 3081-3085
28. Gardiner SM, Kemp PA, Bennett T (1993) Regional haemodynamics in Brattleboro rats during chronic ingestion of $\mathrm{N}^{\mathrm{G}}$-nitro-L-arginine methyl ester. Blood Pressure 2: 228 232

29. Kaech C, Zhu JS, Brechtel G, Baron AD (1993) Acute hypertension induced by L-NMMA causes insulin resistance in rats. Hypertension 22: 470 (Abstract)

30. Krönke KD, Rodriguez ML, Kolb H, Kolb-Bachofen V (1993) Cytotoxicity of activated rat macrophages against syngeneic islets cells is arginine-dependent, correlates with citrulline and nitrite concentrations and is identical to lysis by the nitric oxide donor nitroprusside. Diabetologia $36: 17$ 24

31. Corbett JA, Wang JL, Hugher JH et al. (1992) Nitric oxide and cyclic GMP formation induced by interleukin- $1 \beta$ in islets of Langerhans. Biochem J 287: 229-235

32. Corbett JA, Mikhael A, Shimizu J et al. (1993) Nitric oxide production in islets from nonobese diabetic mice: aminoguanidine-sensitive and -resistant stages in the immunological diabetic process. Proc Natl Acad Sci USA 90: 8992-8995 